\title{
Physicochemical Characterization of Selected Rice (Oryza Sativa L.) Genotypes Based on Gel Consistency and Alkali Digestion
}

\section{Lagat R Chemutai ${ }^{1 *}$, Mawia A Musyoki ${ }^{1}$, Wambua F Kioko ${ }^{1}$, Njagi S Mwenda ${ }^{1}$, Karau G Muriira ${ }^{2}$ and Ngugi M Piero ${ }^{1}$}

${ }^{1}$ Department of Biochemistry and Biotechnology, Kenyatta University, Nairobi, Kenya

${ }^{2}$ Molecular Laboratory, Kenya Bureau of Standards, Kenya

"Corresponding author: Lagat Rose Chemutai, Department of Biochemistry and Biotechnology, Kenyatta University, P. O. Box 43844-00100 Nairobi, Kenya, Tel: +254712848915; E-mail: roselagat76@gmail.com

Rec date: May 26, 2016; Acc date: Jul 19, 2016; Pub date: Jul 22, 2016.

Copyright: (c) 2016 Chemutai LR. This is an open-access article distributed under the terms of the Creative Commons Attribution License, which permits unrestricted use, distribution, and reproduction in any medium, provided the original author and source are credited.

\begin{abstract}
Quality assessment of rice genotypes involves physicochemical and sensory test. A physicochemical test relies on the rice chemical composition, cooking quality, gelatinization temperature and physical properties of cooked rice. The aim of this study was to determine the physicochemical characteristics of selected Kenyan and Tanzanian genotypes based on gel consistency and alkali digestion. Diverse classes of rice exist with different expression levels of gel consistency and alkali digestion. As these traits are major contributors to the eating and cooking quality traits, unscrupulous traders mix both low and high-grade rice hence making enormous profits from their sales. Minitab 17.0 software package was used to determine the means and the standard error of means of the gel consistency physicochemical test results while the alkali digestion values were determined based on the standard evaluation system by International Rice Research Institute. Majority of the genotypes had high alkali digestion. Based on the gel consistency test, the average GC values ranged from $31.50 \mathrm{~mm}$ in ITA 310 to $99.5 \mathrm{~mm}$ in IR 2793 . Genotype BS 217 showed significant difference from Kilombero, IR 64, Kahogo, Saro 5, ITA 310, IR 54, Wahiwahi and BW 196. These results show that physicochemical characterization using the available test procedures can be effectively utilized in analysis of diversity in rice germplasm
\end{abstract}

Keywords: Rice; Gel consistency; Alkali digestion; Physicochemical characterization

\section{Introduction}

Rice belongs to the genus Oryza, which is, divided into four species complexes which include; $O$. sativa, $O$. officialis, $O$. ridelyi and $O$. granulata. The genus contains 25 recognized species where 23 are wild species and two are cultivated species namely; $O$. Sativa and O. glaberrima [1]. The 23 wild species represents the 10 genome types, which are distributed throughout the tropics, and subtropics whereby Africa has five of these genome types. In Kenya and Tanzania, there are many rice varieties, which are either glutinous (waxy) or non-waxy (non-glutinous) with different levels of the amylose content [2].

Rice grain quality traits encompass the totality of all characteristics and features of rice or the rice products that meets the consumer demands and preference [3]. Grain quality features the physical, physiological and its biochemical features [4]. The physical properties include the grain shape, degree of milling, grain appearance, milling recovery, kernel shape. The physicochemical properties comprises of gel consistency (GC), alkali digestion, amylose content (AC) [4-6]. Different rice genotypes have diverse physicochemical and physical properties, which influences the grain quality properties.

These ECQ traits are influenced by complex genetic control of both minor and major quantitative traits loci (QTL), environmental factors and soil's nitrogen levels. QTL analysis indicates that the AC, GC, paste viscosity parameters and gel texture are controlled by the waxy locus $(\mathrm{Wx})$ gene and other minor QTLs. The Wx is located on chromosome six and it encodes granule-bound starch synthase-I (GBSSI), which determines the ratio between amylose and amylopectin in the endosperm starch. Gel consistency measures the cold paste viscosity of cooked milled rice flour an index used in distinguishing cooked rice texture of high amylose genotypes. Gel consistency varies from soft to hard [7]. Genotypes are grouped into arbitrarily set classes based on the length of the gel: hard (length of gel $<40 \mathrm{~mm}$ ), medium (length of gel $41-60 \mathrm{~mm}$ ), and soft (length of gel $>61 \mathrm{~mm}$ ) [8]. Association of starch polymers in the aqueous phase determines weak and rigid gels. , rice with soft gel consistency has a higher preference amongst the consumers. Therefore, breeders tend to develop rice genotypes with soft gel consistency [9].

Alkali digestion quality trait is located on chromosome six and the QTL that controls it is in the alk locus. The alky gene encodes the starch synthase IIa (SSIIa) that determines the gelatinization temperature of cooked rice [10]. Disintegration of rice starch granules in $1.7 \% \mathrm{KOH}$ alkali solution and gelatinization temperature of milled rice have a significant correlation. Alkali digestion values are dependent on the nature of the amylopectin molecules. Amylopectin is a polysaccharide found in the rice starch endosperm. It has a large molecular weight and highly branched compared to amylose. Amylopectin is composed of $\alpha-1-4$-glycosidic linkages that link the Dglucose units while the branched chains are linked by the $\alpha-1-6-$ glycosidic linkages [11].

The starch branching enzymes (SBE) plays a major role in the synthesis of amylopectin since it is the only enzyme that introduces the a-1-6-glycosidic linkages into the a-polyglucans in the endosperm starch, the amylopectin side chains play a major role in the disintegration of rice starch granules in alkali solution $[12,13]$. The degree of polymerization (DP) characterises the amylopectin into four categories [14]. The DP $\leq 12$ forms the A short chains while $13 \leq \mathrm{DP} \leq$ 24 forms the B1 short chains. Moreover, $25 \leq \mathrm{DP} \leq 36$ is attributed to 
the long B2 chains while DP $\geq 37$ forms the B3 long chains. Rice starch granules with amylopectin enriched with the shorter chains easily disintegrates in alkali solution than starch granules that have longer chains of amylopectin [15].

The SSIIa plays a vital role in the elongation of the short amylopectin chains which directly influences the degree of disintegration of the starch molecules in alkali solution [13]. The degree of alkali digestion is inversely proportional to the gelatinization temperature, that is, when the alkali digestion is low, the gelatinization temperature is high [16]. Rice with low GT disintegrates completely in $1.7 \% \mathrm{KOH}$ solution, whereas rice with intermediate GT shows partial disintegration while high GT remains largely unaffected in alkali solution.

\section{Materials and Methods}

\section{Sample collection and preparation}

A total of $500 \mathrm{~g}$ of the rice grains of twelve selected Kenyan and Tanzanian rice genotypes were collected from two repositories; Mwea Irrigation and Agricultural Development (MIAD) and Kilimanjaro Agricultural Training Centre (KATC) in Moshi, Tanzania. The rice grains were brought to Kenyatta University Plant Transformation Laboratory (PTL) and stored under dry conditions with similar moisture content to facilitate further determination physicochemical traits. Rice grains were dehusked to facilitate the alkali digestion test and an electric mill was used to mill dehusked rice into rice flour for gel consistency test. Genotype IR 64 was selected as model genotype since it's a superior variety with soft gel consistency and intermediate alkali digestion (Table 1).

\begin{tabular}{|l|l|l|}
\hline Genotype & Source & Attribute \\
\hline IR 2793 & Kenya & Improved genotype \\
\hline BS 217 & Kenya & Improved genotype \\
\hline BS 370 & Kenya & Improved genotype \\
\hline BW 196 & Kenya & Improved genotype \\
\hline ITA 310 & Kenya & Improved genotype \\
\hline Red Afaa & Tanzania & Landrace genotype \\
\hline IR 54 & Philippines & Improved genotype \\
\hline Kilombero & Tanzania & Landrace genotype \\
\hline IR 64 & Philippines & Improved genotype \\
\hline Kahogo & Tanzania & Landrace genotype \\
\hline Saro 5 & Tanzania & Improved genotype \\
\hline Wahiwahi & Tanzania & Landrace genotype \\
\hline
\end{tabular}

Table 1: Rice genotypes, origin and attributes of rice genotypes used in the study.

\section{Gel consistency}

Gel consistency in rice genotypes was determined using protocol described by [4,7] with slight modifications. Approximately $500 \mathrm{mg}$ rice flour from each rice genotype was weighed in triplicates and placed in a $13 \mathrm{~mm} \times 100 \mathrm{~mm}$ test tube. A total volume of $0.026 \mathrm{ml}$ of $95 \%$ ethanol containing $0.025 \%$ thymol blue was added to each tube and mixed so as to prevent clumping of the rice flour. The mixture was vortexed gently, and then $2 \mathrm{ml}$ of $0.2 \mathrm{~N} \mathrm{KOH}$ was added and vortexed again. Each tube was covered with glass marbles to prevent steam loss and reflux of the samples and placed over a boiling water bath at $920 \mathrm{C}$ for 6 minutes. They were then kept at room temperature for 5 minutes and finally transferred to an ice bath for 15 minutes. The tubes were placed horizontally on a graph paper on a flat laboratory bench for 30 minutes, and the blue gel length was measured from the bottom of the tube to the end of the gel in millimetres (Figure 1). This test was performed in triplicates to ensure accuracy and validity of the results.

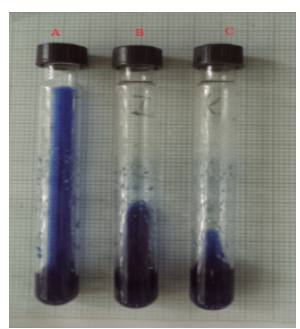

Figure 1: Gel consistency of rice genotypes under study.

\section{Alkali digestion}

Alkali digestion was determined using methodology described by [17] with slight modifications. Disintegration was determined by placing 10 polished rice grains in a Petri plate containing $10 \mathrm{ml}$ of freshly prepared $1.7 \%(\mathrm{w} / \mathrm{v}) \mathrm{KOH}$ solution. Seeds were arranged with the provision of space between the grains for spreading. The Petri plates were then covered and placed in a $30 \mathrm{oC}$ incubator for 23 hours. This test was performed in triplicates to facilitate the accuracy and validity of the test results. The degree of disintegration of each of the grains was rated visually according to standard evaluation system for rice by International Rice Research Institute [18] (Table 2).

\begin{tabular}{|l|l|l|}
\hline Degree of digestion & $\begin{array}{l}\text { Alkali digestion } \\
\text { classification }\end{array}$ & $\begin{array}{l}\text { Alkali digestion } \\
\text { value }\end{array}$ \\
\hline Grain not affected & Low & 1 \\
\hline Grain swollen & Low & 2 \\
\hline $\begin{array}{l}\text { Grain swollen, collar incomplete } \\
\text { and narrow }\end{array}$ & Low & 3 \\
\hline $\begin{array}{l}\text { Grain swollen, collar complete and } \\
\text { wide }\end{array}$ & Intermediate & 4 \\
\hline $\begin{array}{l}\text { Grain split or segmented, collar } \\
\text { complete and wide }\end{array}$ & Intermediate & 5 \\
\hline $\begin{array}{l}\text { Grain dispersed, merging with } \\
\text { collar }\end{array}$ & High & 6 \\
\hline $\begin{array}{l}\text { Grain completely dispersed and } \\
\text { intermingled }\end{array}$ & High & 7 \\
\hline
\end{tabular}

Table 2: The seven-point scale used in assigning of the alkali digestion values. 
Citation: Chemutai LR, Musyoki MA, Kioko WF, Mwenda NS, Muriira KG, et al. (2016) Physicochemical Characterization of Selected Rice (Oryza Sativa L.) Genotypes Based on Gel Consistency and Alkali Digestion. Biochem Anal Biochem 5: 285. doi:10.4172/2161-1009.1000285

Page 3 of 5

\section{Data Analysis}

Data on gel consistency values were transferred to a spreadsheet. The data was subjected to descriptive statistics and expressed as Mean \pm SEM. It was analysed using one-way analysis of variance (ANOVA) followed by Tukey's post hoc test for pair-wise separation and comparison of means. Statistical significance was set at $95 \%$ confidence interval $(\mathrm{P} \leq 0.05)$. Minitab 17.0 software package (State College, Pennsylvania) was used for statistical analysis. Alkali digestion results were descriptive hence; classifications were done visually based on the IRRI standard evaluation system.

\section{Results}

\section{Alkali digestion}
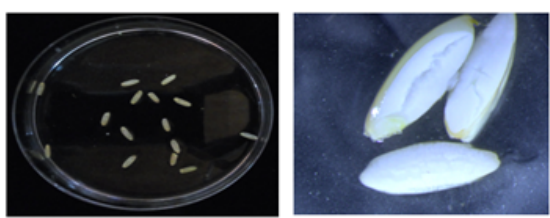

Low alkali digestion
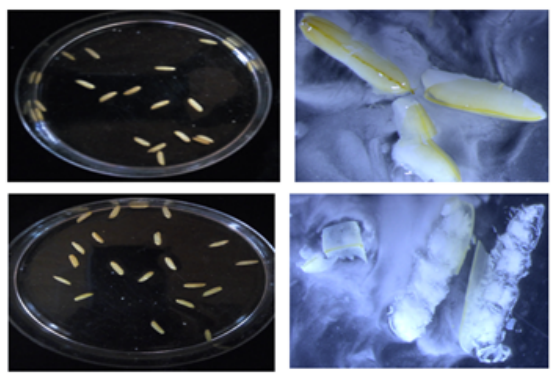

Intermediate alkali digestion

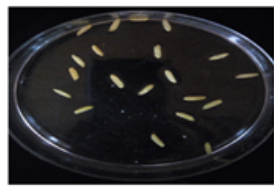

Figure 2: Degree of alkali digestion in rice genotypes under study.

\begin{tabular}{|l|l|l|}
\hline Genotype & Degree of degradation & Alkali digestion value [ADV] \\
\hline IR 2793 & Intermediate & 4.0 \\
\hline BS 217 & Intermediate & 5.0 \\
\hline BS 370 & Intermediate & 5.0 \\
\hline BW 196 & High & 6.0 \\
\hline ITA 310 & High & 7.0 \\
\hline Saro 5 & High & 6.0 \\
\hline IR 64 & Intermediate & 4.0 \\
\hline Kilombero & High & 7.0 \\
\hline Red Afaa & Low & 1.0 \\
\hline Kahogo & High & 7.0 \\
\hline IR 54 & High & 7.0 \\
\hline Wahiwahi & High & 7.0 \\
\hline
\end{tabular}

Table 3: Degree of degradation, alkali digestion values of the 12 genotypes.
Based on the degree of alkali digestion observed (Figure 2), the rice genotypes were classified into three groups; low, intermediate and high alkali digestion values. Genotype with low degree of alkali digestion value was Red Afaa while four genotypes had intermediate alkali digestion namely; IR 2793, BS 217, BS 370 and IR 64. High alkali digestion was observed in 7 genotypes; Saro 5 and BW 196 had an alkali digestion value of 6.0 while Wahiwahi, ITA 310, IR 54, Kahogo and Kilombero had an alkali digestion value of 7.0 (Table 3 ).

\section{Gel consistency (GC)}

Based on GC values shown in Table 4, the average GC values ranged from $31.50 \mathrm{~mm}$ in ITA 310 to $99.5 \mathrm{~mm}$ in IR 2793. Genotype BS 217 had the second highest GC values after IR 2793 with no significant differences amongst their mean values. There was no significant difference between the GC values of BS 217, Red Afaa and BS 370 (P $\geq$ 0.05; Table 4). Gel consistency values of BS 370, an improved Kenya genotype, revealed no significant difference from Kahogo, BW 196, Saro 5, IR 64, Kilombero and Red Afaa (P $\geq 0.05$; Table 4). Genotypes BS 370, BW 196, Saro 5, IR 64, Kilombero, Kahogo, IR 54 and Wahiwahi had no significant difference in gel consistency values. Improved genotypes, ITA 310 and IR 54, had gel consistency values insignificantly different from Wahiwahi, a landrace genotype from Tanzania ( $\mathrm{P} \geq 0.05$; Table 4$)$

Gel consistency value of genotype BS 217, an improved Kenyan rice genotype was significantly different from Kilombero, IR 64, Kahogo, Saro 5, ITA 310, IR 54, Wahiwahi and BW $196(\mathrm{P}<0.05$; Table 4). Genotype Red Afaa showed significant difference in the mean gel consistency measurements from genotypes ITA 310, Wahiwahi and IR 54 values $(\mathrm{P}<0.05$; Table 4$)$. Improved genotype ITA 310 with mean GC value of $31.50 \mathrm{~mm}$ showed significant difference from nine rice genotypes except Wahiwahi and IR $54(\mathrm{P}<0.05$; Table 4$)$. The GC value of improved Kenyan genotype IR 2793, was significantly different from the gel consistency values of genotypes ITA 310, Wahiwahi, IR 54, Saro 5, BW 196, Kahogo, IR 64, Kilombero and BS $370(\mathrm{P}<0.05$; Table 4).

\begin{tabular}{|l|l|}
\hline Genotype & Gel consistency values $(\mathbf{m m})$ \\
\hline IR 2793 & $99.50 \pm 0.50 \mathrm{a}$ \\
\hline BS 217 & $97.00 \pm 1.29 \mathrm{ab}$ \\
\hline BS 370 & $75.25 \pm 3.90 \mathrm{bcd}$ \\
\hline BW 196 & $67.00 \pm 3.39 \mathrm{~cd}$ \\
\hline ITA 310 & $31.50 \pm 4.48 \mathrm{e}$ \\
\hline Saro 5 & $66.50 \pm 3.48 \mathrm{~cd}$ \\
\hline IR 64 & $67.75 \pm 3.42 \mathrm{~cd}$ \\
\hline Kilombero & $69.50 \pm 3.07 \mathrm{~cd}$ \\
\hline Red Afaa & $78.50 \pm 9.54 \mathrm{abc}$ \\
\hline Kahogo & $67.50 \pm 5.50 \mathrm{~cd}$ \\
\hline IR 54 & $53.25 \pm 7.09 \mathrm{de}$ \\
\hline Wahiwahi & $54.25 \pm 3.33 \mathrm{de}$ \\
\hline
\end{tabular}

Table 4: Analysis of variance of the gel consistency values of the 12 rice genotypes. 


\section{Discussion}

Evaluation of the rice grain quality traits is achieved through the determination of the physicochemical properties of the rice starch, which provides an indirect index on the eating and cooking quality trait of each genotype. Determination of the ECQ traits is imperative given that it influences the multiple uses of rice at both industrial and domestic scale [19]. Genetic background and environmental interactions cause a variation in ECQs of different germplasms [20].

Alkali digestion is one of the important indicators of the eating, cooking and processing quality of rice starch [12]. In this study, determination of the alkali digestion classified the rice genotypes into three groups namely; low, intermediate and high alkali digestion. Similar classifications have been reported in Thai rice cultivars [21]. Genotypes that were least affected by the alkali solution had a low $\mathrm{ADV}$, which could be attributed to the presence of more long amylopectin chains (B2 and B3) than the short (A and B1) amylopectin chains [15]. The activity of the SSIIa is highest in the low alkali digestion cluster than in other classification. This is due to the SSIIa gene increasing the proportion of the short amylopectin chains [13]. Given that there is an inversely proportional relationship between alkali digestion value and the gelatinization temperature, the genotypes with low alkali digestion have a high gelatinization temperature above $[22,23]$.

The intermediate alkali digestion group consisted of grains that were either swollen or segmented with complete and wide collars. Similar observations have been reported by in Myanmar local rice cultivars and in Thai rice cultivars $[21,24]$. This observation could be attributed to the presence of intermediate number of both the long and the short chains. The SSIIa plays a vital role in the elongation of the short amylopectin chains which directly influences the degree of disintegration of the starch molecules in alkali solution. Hence, the SSIIa activity is lower than the low ADV classification and higher than the SSIIa activity of the high alkali digestion cluster [13]. The intermediate ADV corresponds to an intermediate gelatinization temperature, which ranges from 70 to 74 The intermediate alkali digestion genotypes are the most preferred worldwide given their good cooking qualities such as water absorption, moistness, volume expansion and softness upon cooling [25].

The rice grains that were highly affected by alkali solution had a high ADV. This observation could be attributed to the presence of amylopectin with a high number of short chains (A and B1) with minimal number of long amylopectin chains. The SSIIa activity is maximal amongst these genotypes since this gene plays a vital role in the elongation of the short amylopectin chains $[13,26]$. The high alkali disintegration corresponds to gelatinization temperature below. The low gelatinization temperature ascribed to these genotypes is an economically important indicator of quality given that consideration of the shorter cooking duration results in significant savings of the fuel costs. Consumer preference of the low GT rice is minimal due to the negative outcome on the linear kernel elongation, water absorption and volume expansion of the rice genotypes [27]. The diverse ADV classification of IR 54 and IR 64, despite both genotypes being improved genotypes from Philippines, is attributed to crop improvement strategies that have been undertaken on both crops. The IR64 rice genotype is a superior rice genotype released by IRRI after undergoing crop improvement process to confer good quality traits [28] as well as resistance to biotic stress such as Xanthomonas oryzae and abiotic stresses, such as flooding [29].
Gel consistency test was developed as an indirect method used in screening cooked rice for its hardness especially in rice with high amylose content [30]. This physicochemical test is used in rice improvement programs to ascertain if high amylose genotypes are soft or hard textured when cooked [31]. In this study, genotypes were classified into the soft, intermediate and hard GC based on the gel consistency values [8]. The three classifications could be as a result of different expression levels of the waxy gene and the variations in the Wx gene locus [32].

Hard gel consistency observed in this study was due to formation of rigid rice gels, which occur as a result association of starch polymers in the aqueous phase. Amylose polymers leach when the starch granules are heated and they subsequently form networks once the gel cools [33-35]. Physicochemical characterization of double haploid rice population also reported on the same classification [36]. The intermediate gel consistency observed in this study could be due to effects of minor genes, for instance, gene interaction between waxy and pullulanase or waxy and BEIII genes [36]. Indian cultivars Sharbati and $\mathrm{HBC}-19$ expressed intermediate GC values of 54, 58 and $53 \mathrm{~mm}$ respectively [37].

Genotypes with soft GC had a gel length that is more than $61 \mathrm{~mm}$. This trait was observed in most of the rice genotypes under study. The model variety IR 64 had an average GC of $67.75 \mathrm{~mm}$, which is a soft gel consistency genotype [28]. The IR 64 classification in this study was contrary to earlier studies, which classified IR 64 under the hard gel consistency category [38]. Traditional aromatic Indian BS 370 rice genotype had an intermediate GC, which was different from findings of this study where Kenyan BS 370 had a GC value of $75.25 \mathrm{~mm}$ [39]. The different classification of IR 64 and BS 370 could be attributed to different environmental conditions when these studies were done. The soft and hard GC values are accounted for by the biallelic variability at the waxy locus [32]. The wide diversification of the physicochemical test results was due to the wide genetic background of the rice genotypes under study, that is, the rice composed of landraces and improved rice genotypes from different geographical regions. Similar classification of rice into three GC groups has been reported in 63 nonwaxy rice varieties $[40,41]$.

\section{Conclusion}

From this study, it can be concluded that physicochemical classification showed considerable variation based on gel consistency and alkali digestion. Most of the rice genotypes under study had high alkali digestion values implying that it saves on fuel cost. In addition, these verities compromises on the linear kernel elongation, water absorption and volume expansion hence tend to have poor eating and cooking quality traits. Soft gel consistency was also the most observed trait, which is a favorable trait amongst rice since they remain soft after cooling.

\section{References}

1. Sanni KA, Tia DD, Ojo DK, Ogunbayo AS, Sikirou M, et al. (2013) Diversity of rice and related wild species in Africa. Realizing Africa's rice promise CAB International, Wallingford 79-87.

2. Musyoki MA, Kioko WF, Mathew NP, Muriira KG, Wavinya ND, et al. (2015) Genetic diversity studies on selected rice (Oryza sativa L.) Genotypes based on amylose content and gelatinization temperature. Advances in Crop Science and Technology 3: 193-199. 
3. Siddiqui SU, Kummamaru T, Satoh H (2007) Pakistan rice genetic resources-I: Grain morphological diversity and its distribution. Pakistan Journal of Botany 39: 841-848.

4. Sattari A, Mahdinezhad N, Fakheri B, Noroozi M, Beheshtizadeh H (2015) Improvement of the eating and cooking qualities of rice: a review. International Journal of Farming and Allied Sciences 4: 153-160.

5. Cruz ND, Khush GS (2000) Rice grain quality evaluation procedures. Aromatic Rices 3: 15-28.

6. Rohilla R, Singh VP, Singh US, Singh R, Khush GS (2000) Crop husbandry and environmental factors affecting aroma and other quality traits. Aromatic Rices 201-216.

7. Cagampang GB, Perez CM, Juliano BO (1973) A gel consistency test for eating quality of rice. Journal of Science of Food and Agriculture 24 1589-1594.

8. Graham R (2002) A proposal for IRRI to establish a grain quality and nutrition research center. Los Baños IRRI.

9. Wang LQ, Liu WJ, Xu Y, He YQ, Luo LJ, et al. (2007) Genetic basis of 17 traits and viscosity parameters characterizing the eating and cooking quality of rice grain. Theoretical and Applied Genetics 115: 463-476.

10. Fan CC, Yu XQ, Xing YZ, Xu CG, Luo LJ, et al. (2005) The main effects epistatic effects and environmental interactions of QTLs on the cooking and eating quality of rice in a doubled-haploid line population. Theoretical and Applied Genetics 110: 1445-1452.

11. Nakamura Y, Sakurai A, Inaba Y, Kimura K, Iwasawa N, et al. (2002) The fine Structure of Amylopectin in Endosperm from Asian Cultivated Rice can be largely classified into two Classes. Starch-Stärke 54: 117-131.

12. Nishi A, Nakamura Y, Tanaka N, Satoh H (2001) Biochemical and genetic analysis of the effects of amylose-extender mutation in rice endosperm. Plant Physiology 127: 459-472.

13. Umemoto T, Yano M, Satoh H, Shomura A, Nakamura Y (2002) Mapping of a gene responsible for the difference in amylopectin structure between japonica-type and indica-type rice varieties. Theoretical and Applied Genetics 104: 1-8.

14. Hanashiro I, Abe JI, Hizukuri S (1996) A periodic distribution of the chain length of amylopectin as revealed by high-performance anionexchange chromatography. Carbohydrate Research 283: 151-159.

15. Umemoto T, Terashima K, Nakamura Y, Satoh H (1999) Differences in amylopectin structure between two rice varieties in relation to the effects of temperature during grain-filling. Starch-Stärke 51: 58-62.

16. Gao Z, Zeng D, Cui X, Zhou Y, Yan M, et al. (2003) Map-based cloning of the ALK gene which controls the gelatinization temperature of rice. Science in China Series C: Life Sciences 46: 661-668.

17. Little RR, Hilder GB, Dawson EH (1958) Differential effect of dilute alkali on 25 varieties of milled white rice. Cereal Chemistry 35: 111-126.

18. International Rice Research Institute (1996) Standard evaluation system for rice. IRRI Los Banos Philippines.

19. Hsu YC, Tseng MC, Wu YP, Lin MY, Wei FJ, et al. (2014) Genetic factors responsible for eating and cooking qualities of rice grains in a recombinant inbred population of an inter-sub specific cross. Molecular Breeding 34: 655-673.

20. Yan CJ, Tian ZX, Fang YW, Yang YC, Li J, et al. (2011) Genetic analysis of starch paste viscosity parameters in glutinous rice (Oryza sativa L.). Theoretical and Applied Genetics 122: 63-76.

21. Prathepha P, Daipolmak V, Samappito S, Baimai V (2005) An assessment of alkali degradation waxy protein and their relation to amylose content in Thai rice cultivars. Science Asia 31: 69-75.

22. Juliano BO (2003) Rice chemistry and quality. Manila Philippines: Philippine Rice Research Institute.
23. Waters DL, Henry RJ, Reinke RF, Fitzgerald MA (2006) Gelatinization temperature of rice explained by polymorphisms in starch synthase. Plant Biotechnology Journal 4: 115-122.

24. Aung P, Nishi A, Kumamaru T, Satoh H (2004) The amylopectin chains length distribution of opaque endosperm type in Myanmar local rice cultivar. Rice Genetics Newsletter 19: 67-69.

25. Sthapit BR, Upadhyay MP, Shrestha PK, Jarvis DI (2004) On-farm conservation of agricultural biodiversity in Nepal. Volume II. Managing diversity and promoting its benefits. In Proceedings of the Second National Workshop.

26. Nakamura Y, Francisco PB, Hosaka Y, Sato A, Sawada T, et al. (2005) Essential amino acids of starch synthase IIa differentiate amylopectin structure and starch quality between japonica and indica rice varieties. Plant Molecular Biology 58: 213-227.

27. Tuano PP, Umemoto T, Aoki N, Nakamura Y, Sawada T, et al. (2011) Grain quality and properties of starch and amylopectin of intermediateand low-amylose indica rices. The Philippine Agricultural Scientist 94: 140-148.

28. Khush GS (2005) What it will take to feed 5.0 billion rice consumers in 2030. Plant Molecular Biology 59: 1-6.

29. Swamy P, Panchbhai AN, Dodiya P, Naik V, Panchbhai SD, et al. (2006) Evaluation of bacterial blight resistance in rice lines carrying multiple resistance genes and Xa21 transgenic lines. Current Science 90: 818-824.

30. Juliano BO (1985) Criteria and tests for rice grain qualities. In: Juliano BO (ed) Rice chemistry and technology (2ndedn) American Association of Cereal Chemists Inc MN 43-524.

31. Tran NA, Daygon VD, Resurreccion AP, Cuevas RP, Corpuz HM, et al (2011) A single nucleotide polymorphism in the Waxy gene explains a significant component of gel consistency. Theoretical and Applied Genetics 123: 519-525.

32. Wanchana S, Toojinda T, Tragoonrung S, Vanavichit A (2003) Duplicated coding sequence in the waxy allele of tropical glutinous rice (Oryza sativa L.). Plant Science 165: 1193-1199.

33. Dea ICM (1989) Industrial polysaccharides. Pure and Applied Chemistry 61: 1315-1322.

34. Nguyen QD, Jensen CT, Kristensen PG (1998) Experimental and modelling studies of the flow properties of maize and waxy maize starch pastes. Chemical Engineering Journal 70: 165-171.

35. Lii CY, Tsai ML (2000) Effect of hot-water-soluble components on the rheological properties of rice starch. Starch-Stärke 52: 44-53.

36. He Y, Han Y, Jiang L, Xu C, Lu J, et al. (2006) Functional analysis of starch synthesis genes in determining rice eating and cooking qualities. Molecular Breeding 18: 277-290.

37. Ritika BY, Khatkar BS, Yadav BS (2010) Physicochemical morphological thermal and pasting properties of starches isolated from rice cultivars grown in India. International Journal of Food Properties 13: 1339-1354.

38. Biswas SK, Juliano BO (1988) Laboratory parboiling procedures and properties of parboiled rice from varieties differing in starch properties. Cereal Chemistry 65: 417-423.

39. Singh RK, Singh US, Khush GS (1997) Indigenous Aromatic Rices of India: Present Scenario and Needs. Agricultural Situation in India 54: 491-496.

40. Tan Y, Corke H (2002) Factor analysis of physicochemical properties of 63 rice varieties. Journal of the Science of Food and Agriculture 82: 745-752.

41. Kim HY, Kim KM (2016) Mapping of grain alkali digestion trait using a Cheongcheong/Nagdong doubled haploid population in rice. Journal of Plant Biotechnology 43: 76-81. 